\title{
Socioeconomic Inequalities in Staff Physical Activity: Evidence from the SHAHWAR Cohort Study in Iran
}

\section{Maryam Khoramrooz}

Shahroud University of Medical Sciences: Shahrood University of Medical Sciences

\section{Fariba Zare}

Shahroud University of Medical Sciences: Shahrood University of Medical Sciences

\section{Farideh Sadeghian}

Shahroud University of Medical Sciences: Shahrood University of Medical Sciences

\section{Ali Dadgari}

Shahroud University of Medical Sciences: Shahrood University of Medical Sciences

\section{Reza Chaman}

Shahroud University of Medical Sciences: Shahrood University of Medical Sciences

\section{Seyed mohammad Mirrezaie ( $\nabla$ mirrezaie@shmu.ac.ir)}

Shahroud University of Medical Sciences: Shahrood University of Medical Sciences https://orcid.org/0000-0001-5352-4244

\section{Research}

Keywords: Physical activity, Socioeconomic Inequalities, Staff, Medical Sciences University, Iran

Posted Date: July 13th, 2021

DOI: https://doi.org/10.21203/rs.3.rs-659489/v1

License: (c) (1) This work is licensed under a Creative Commons Attribution 4.0 International License. Read Full License 
3 Maryam Khoramrooz $^{1}(\mathrm{PhD})$, Fariba Zare $^{1}(\mathrm{MSc})$, Farideh Sadeghian ${ }^{1}(\mathrm{PhD})$, Ali Dadgari ${ }^{2,1}$

4 (PhD), Reza Chaman ${ }^{3,1}(\mathrm{MD}, \mathrm{PhD})$ and Seyed Mohammad Mirrezaie ${ }^{4,1 *}(\mathrm{MD})$

\section{Socioeconomic Inequalities in Staff Physical Activity: Evidence from the SHAHWAR}

\section{Cohort Study in Iran}

1. Center for Health Related Social and Behavioral Sciences Research, Shahroud University of Medical Sciences, Shahroud, Iran

2. School of Nursing and Midwifery, Shahroud University of Medical Sciences, Shahroud, Iran

3. Department of Epidemiology, School of Public Health, Shahroud University of Medical Sciences,

Shahroud, Iran

10

4. Clinical Research Development Unit, Imam Hossein Hospital, Shahroud University of Medical Sciences, Shahroud, Iran

* Correspondence: Seyed Mohammad Mirrezaie, Assistant Professor of Preventive \& Community Medicine, Clinical Research Development Unit, Imam Hossein Hospital, Shahroud University of Medical Sciences, Shahroud, Iran. Workplace Phone: +98 2332394091, Fax; +9823 32394852, Cell: +989123047255 E-mail: mirrezaie@shmu.ac.ir

6

17

8

19

0

21

2

3


Abstract:

25 Background: This study was aimed to investigate socioeconomic-related inequality in physical activity (PA) among Staff of Medical Sciences University in Shahroud, Iran.

27 Methods: Data were extracted from the first phase of the SHAHWAR cohort study. The 28 Concentration index (CI) and Wagstaff decomposition method were applied to determine 29 socioeconomic-related inequality in PPA and its contributors, respectively.

Results: CIs of poor total PA (PTPA) and poor work-related PA (PWRPA) were 0.092 and 0.141,

31 indicating their more concentration among staff of higher socioeconomic groups. Furthermore, the 32 negative CI of poor leisure-time PA (PLTPA) (-0.191) suggests that it disfavors staff from lower socioeconomic groups. While PWRPA, Subjective social status (SSS), socioeconomic status 34 (SES), and gender were positively contributed to the measured inequality in PTPA $(65.3 \%, 37.9 \%$, $18.6 \%$, and $16.6 \%$, respectively), residence in urban areas and PLTPA have negative contributions 36 (64\% and 27\%, respectively). Similarly, SES, marital status, and residence in urban areas 37 positively contributed to the inequality of PLTPA by $53.4 \%, 36.2 \%$, and $23.5 \%$ respectively. Whereas, gender had the most negative contribution by $28.7 \%$. Residence in urban areas, SES, 39 SSS, and shift work were all positively contributed to the measured inequality in PWRPA (its more concentration among staff from high SES groups) by $28.4 \%, 20 \%, 15.2 \%$, and $12.7 \%$, respectively,

41 while the opposite is true for gender by the contribution of $13.3 \%$.

42 Conclusions: Different patterns of PPA inequality revealed that health promotion programs should 43 aim to educate and support higher SES staff to increase their PA in workplace, leisure time, and 44 transportation, and lower SES staff to increase their leisure-time PA.

45 Keywords: Physical activity, Socioeconomic Inequalities, Staff, Medical Sciences University, 46 Iran 


\section{Background}

48 Physical activity (PA) has several health benefits, including lower risk of heart disease, stroke, 49 type 2 diabetes, breast cancer, colon cancer, [1] and better mental health, [1] [2] and it increase 50 life expectancy. [1] It also could increase the employees' productivity [3, 4] and reduce their sick

51 leave, $[4,5]$ and healthcare costs [6] by creating a healthier workforce. The results of a study 52 indicates that healthcare costs for employees who were active and very active were about $\$ 250$ 53 less than that of sedentary employees. [6]

54 Studies around the world indicate that several demographic and socioeconomic factors such as 55 age, gender, education, occupation, income and mental health are associated with PA and its four 56 domains. [2, 7-9] Furthermore, there are different patterns of the impact of SES on PA among its 57 different domains. [10] There are some evidence which indicate that while occupational PA was 58 further prevalent among the lower socioeconomic groups, [7, 10, 11] leisure time PA was more 59 prevalent among people with higher SES. [10, 12]

60 Governments often implement health promotion programs to increase public health. In this regard, 61 the workplace of people is one of the appropriate settings for the implementation of these 62 programs. $[13,14]$ Because employed people spend a significant proportion of their time at work. 63 [10] Moreover, the return on investment on employees' PA is high [15] because of its favorable 64 effects on productivity, absenteeism, and healthcare costs. Designing cost-effective interventions 65 requires analyzing the current situation of PA distribution among different socioeconomic groups 66 and understanding its contributing factors. In Iran, some studies have been conducted on the impact 67 of socioeconomic status on PA in the general population. However, the employees' PA has not 68 been the focus of these studies. [16-18] This study was designed to provide further evidence for 
public health policy to address socioeconomic inequalities of poor physical activity (PPA) and its

70 different domains among staff of medical sciences university in Shahroud, Iran.

\section{Methodology}

\section{Source of data and variables}

73 In the present study, data were extracted from the first phase of the SHAHWAR (SHAhroud 74 Healthcare Workers Associated Research) cohort study which was started from 2, OCT, 2019 in 75 Shahroud, located in the Northeast of Iran. SHAHWAR is a subset of PERSIAN Cohort study [19] 76 and focuses on the health of employees. In this cohort study, data from 1178 personnel of Shahroud 77 University of Medical Sciences was prospectively collected after obtaining informed consent. After cleaning data and excluding subjects with missing observations, a total of 1157 staff were

79 included in the analysis. The SHAHWAR cohort study was approved by the Ethics Committee of Shahroud University of Medical Sciences (IR.SHMU.REC.1397.033).

81 In the SHAHWAR cohort study, data for participants' PA were measured using the Persian version 82 of the International PA Questionnaire (IPAQ), a valid and reliable questionnaire that was prepared to assess the participants' PA in the PERSIAN cohort study. The questionnaire measures the 84 amount of PA in four domains of occupational, transportation, household or gardening, and 85 leisure-time activities. The outcome variables were poor physical activity in total (PTPA) and in 86 its four domains including: poor leisure-time PA (PLTPA), poor domestic and gardening activities 87 (PDGA), poor transport-related PA (PTRPA), and poor work-related PA (PWRPA). Participants 88 were categorized as having poor physical activity in total and in each domain of PA if their activity 89 was less than its median level. The medians (interquartile ranges) for leisure time PA, domestic 90 and gardening activities, work-related PA, transport-related PA, and total PA were $3.3(0,12.6), 6$ 91 (2.3, 14), $20.8(5,63.4), 30.9(20,47.4)$, and 89.5 (53.6, 133.1) METs-hour/week, respectively. 
92 The principal component analysis (PCA) was used to construct an index of socioeconomic status

93 (SES) for participants. [20] SES index is derived from a factor analysis of preliminary variables

94 that included: household assets and properties, entertainment and travel related variables,

95 education and access to information and occupational variables. SES scores obtained from PCA

96 were used to classify participants into the five SES quintiles from the lowest (1st quintile) to the

97 highest (5th quintile).

98 One another variable which was measured in this study was subjective social status (SSS); the

99 social class that staff consider to belong it (lowest, low, medium, high, highest). Other the study 100 explanatory variables were as follows: gender, age, household size, marital status, job profession, 101 having secondary job and shift working.

102 Inequality measurement

103 In this study, we used the familiar concentration index (CI) approach [21] to measure 104 socioeconomic inequalities in staff PPA. The calculation of CIs for PPA was based on the 105 concentration curve (CC) which shows the degree of inequality by plotting the cumulative 106 percentage of PPA on the Y-axis against the cumulative percentage of SES score on the X-axis. 107 The $\mathrm{CI}$ is calculated as twice the area between the $\mathrm{CC}$ and the line of equality. The value of CI 108 ranges from -1 to +1 . If $\mathrm{CC}$ lies above (below) the line of equality, the $\mathrm{CI}$ takes a negative 109 (positive) value, indicating that PPA was more concentrated among staff with lower (higher) SES. 110 When the CC crosses the line of equality, the CI equals zero which implies that PPA was equally 111 distributed among staff from different socioeconomic strata. The conventional CIs of the PPA as 112 a whole and in its four domains were calculated as follows:

$113 \quad c=\frac{2}{n \mu} \sum_{i=1}^{n} y_{i} r_{i}-1$ 
115 In the equation above, $c$ is the conventional CI, $y_{i}$ is PPA of $i$-th staff, $r_{i}$ is the fractional rank of $116 i$-th staff in the distribution of their SES, and $\mu$ is the mean of PPA. Since the outcome variables 117 were binary, we used the Wagstaff approach [22] to normalize the conventional CIs of PPA using 118 the formula below:

$119 \quad C=\frac{c}{(1-\mu)}$

120 Where $C$ is the Wagstaff normalized CI.

121 Decomposition of inequality

122 As it is shown by Wagstaff et al [23], measured inequality in health outcomes can be decomposed

123 to the sum of contributions of its associated factors (the explained component) and an unexplained

124 residual component. In the present study, we used this approach to quantify the contribution of the

125 study explanatory variables to the measured inequality in PPA using the formula below:

$126 \quad C=\sum_{k}\left(\frac{\beta_{k} \bar{X}_{k}}{\mu}\right) C_{k}+\frac{C_{e}}{\mu}$

127 Where $\beta_{k}$ is the marginal effect of the $k_{t h}$ explanatory variable on the PPA (estimated using the 128 legit regression model), $\bar{X}_{K}$ is the mean of $k_{t h}$ explanatory variable and $\mu$ is the mean of PPA. The 129 first component of the $C$ is the sum of absolute contributions of the explanatory variables to the 130 measured CI which was calculated through multiplying the elasticity of PPA with respective to the

131 explanatory variables $\left(\frac{\beta_{k} \bar{X}_{k}}{\mu}\right)$ by their CIs $\left(C_{k}\right)$. The residual component $\left(\frac{C_{e}}{\mu}\right)$ is the part of the 132 measured inequality in PPA that has not been explained by the study explanatory variables.

133 All the study analyses were performed by the Stata software version 14. [24]

\section{Results}


135 Table 1 shows descriptive statistics for staff of Medical Sciences University in total and by all 136 types of PPA. The results of the descriptive analysis indicated that prevalence of PTPA among 137 females was higher than males (53.1\% vs. $45.3 \%)$ and it increased with age. Divorced/Widowed 138 staff have the lowest prevalence of PTPA compared to the single and married staff (29.3\% vs. $13951.1 \%$ and 51\%, respectively). Also the proportion of PTPA was highest in office workers $(67.9 \%)$ 140 and lowest in technical/service staff (36.3\%). Staff who have the household size of 5 and more, 141 were shift worker, have secondary job, and use car have lower prevalence of PTPA than their 142 counterparts. Furthermore, PTPA among staff with the highest SES was more prevalent than who 143 have the lowest SES (54.6\% vs. 41\%). Staff with the highest SSS have the lowest prevalence of 144 PTPA (41.5\%) than other social strata. Also, the proportion of PTPA among staff who have 145 PLTPA, PDGA, PTRPA, and PWRPA was higher than their counterparts. In the same way, the 146 prevalence PPA in different domains of PA in terms of the staff characteristics was shown in 147 Table1.

148 The CCs and CIs of all types of PPA are presented in Figure1 and Table 2, respectively. The CCs 149 of PTPA and PWRPA which are below the line of equality, and their positive and statistically 150 significant CIs show that poor total PA and work-related PA were more prevalent amongst staff 151 from higher socioeconomic strata. However, The CC of PLTPA lies above the line of equality and 152 its CI was negative and statistically significant, indicating that socioeconomic inequality in leisure 153 time PA favors higher SES groups (e.g. it is more concentrated among staff from lower SES 154 groups). The CCs of PDGA and PTRPA cross the line of inequality and their CIs were not 155 statistically different from zero, suggesting that there were no socioeconomic inequalities in 156 distribution of poor domestic and gardening activities and transport-related PA. 
157 Table 3 represents the results of decomposition of socioeconomic inequality in PTPA, PLTPA, 158 and PWRPA. Having PWRPA, SSS, SES, and gender were the main contributors that increase the 159 prevalence of PTPA among staff from higher SES groups by 65.3\%, 37.9\%, 18.6\%, and 16.6\%, 160 respectively. In contrast, the more negative contributions of residence in urban areas (64\%) and 161 having poor leisure time PA (27\%) show that these factors mainly reduce the concentration of 162 PTPA among staff from the higher SES groups. Similarly, SES, marital status, and residence in 163 urban areas positively contributed to the more concentration of PLTPA among staff of lower SES 164 groups by $53.4 \%, 36.2 \%$, and $23.5 \%$ respectively. Also, gender had the most negative contribution $165(28.7 \%)$ to the measured inequality in PLTPA. Residence in urban areas, SES, SSS, and shift work 166 were all positively contributed to the measured inequality in PWRPA (its more concentration 167 among staff from high SES groups) by $28.4 \%, 20 \%, 15.2 \%$, and $12.7 \%$, respectively, while the 168 opposite is true for gender by the contribution of $13.3 \%$

\section{Discussion}

170 The present study is the first study which investigated socioeconomic inequalities in PPA among

171 the Iranian staff of medical sciences universities.

172 Our study revealed several issues: 1) the positive CI of 0.092 indicates that higher SES staff tend 173 to have more PPA than their lower SES counterparts; 2) different areas of PA show different 174 patterns of socioeconomic inequality; and 3) the positive CI of 0.141 indicates that PWRPA was 175 found more often among staff belonging to higher socioeconomic strata, while the negative CI of $176-0.191$ suggests that PLTPA was found more often among the staff from lower socioeconomic 177 strata.

178 This study also showed that more than half $(65.3 \%)$ of the measured inequality in PPA was 179 attributable to the PWRPA. In contrast, PLTPA and PTRPA were accounted for $27 \%$ and $18.6 \%$ 
180 of the measured inequality in PPA, respectively. In consistence with the results of Vandelanotte et 181 al's study, [25] the results of the present study indicated that both PWRPA and PLTPA could 182 increase the likelihood of PPA as a whole. This also was true for PPA in transportation. However, 183 more PA in leisure time and active transportation (including cycling and walking) could not fully 184 compensate the less occupational PA. Being from higher socioeconomic groups provides more 185 opportunities to have more PA in leisure time [26] and active transportation. [27] There seem to 186 be reasons why despite having more opportunities for being physically active in leisure time and 187 active transportation, total PA among the staff with higher SES stay low: one reason is that the 188 high opportunity cost of leisure-time PA and active transportation may reduce tendency of higher 189 SES staff to increase their PA in these domains. [8, 28, 29] Furthermore, some studies have shown 190 that walkable built environment has a greater impact on active transportation in higher 191 socioeconomic groups than their lower counterparts. [30, 31] Therefore, unsuitable walkable 192 environment could be the reason for lower active transportation of higher SES staff in our study. 193 SSS, SES, and female gender were the next important factors that positively contributed to the 194 socioeconomic inequality in staff PPA, whereas residence in urban areas had the most negative 195 contribution to this inequality. In our study, the probability of PPA was different among staff with 196 different SSSs. This is consistent with the results of Frerichs ET als' study in four Asian countries 197 which shows that there is an association between SSS and people's weekly or daily PA. [32] The 198 results of other studies indicate that people's social norms, values and beliefs play an important 199 role in their health behaviors, including PA. [33, 34] In our study, it seems that social norms, values 200 and beliefs towards PA among higher SES staff has led them to be less physically active than their 201 lower SES counterparts. 
202 Our study highlighted the more percentage of PPA among higher SES staff. The results of 203 Humphreys and Ruseski's study show that people with higher SES (including income, education, 204 and employment), are less probable to participate in PA. Due to their higher wages, being 205 physically active outside the workplace have more opportunity cost for them. So, they are less 206 likely to spend a lot of time on PA outside the workplace. [8] The results also suggested that female 207 participants were more likely to have PPA than their male counterparts. Other studies in Iran show 208 that PPA is significantly more common in women than men. [35, 36] Similar finding was seen in 209 Abu Saad et al's study which indicated that female health care workers were less physically active 210 than males. [7] With a different result a study was performed in Malaysia indicate that gender is 211 not related to PA in health care workers. [37] It seems the smaller sample size in Jamil et al's study 212 to be the main reason for this difference. Lack of structure for opportunities within their 213 communities, cultural constraints, economic, social, and personal home expectations are the main 214 factors that restrict women's leisure-time PA [38] which could decrease their total PA as a whole. 215 Residence in urban areas decreased the probability of staff's PPA. This result is in line with the 216 results of Bauman et al's study in six Asia-Pacific countries. [39] Since urban resident staff found 217 more frequently among higher socioeconomic groups, they usually have more access to the parks, 218 recreation and sport facilities which were cited as the facilitators of leisure-time PA in other 219 studies. [40, 41] In addition, as it is showed in other studies, even though people have equal access 220 to recreational and other facilities for PA, the extent to which they use these facilities is affected 221 by the quality of them [42-44] and social and cultural factors inherent in their residential area [42, 222 45] which could negatively affect the rural resident staff' decisions related to their PA in leisure 223 time. 
224 Studies show that workplace and leisure time PA each have different effects on an individual's

225 health. [46, 47] In this regard, the findings of the present study provide some evidences to design

226 interventions on socioeconomic inequalities in two domains of work-related and leisure-time PA.

227 Residence in urban areas was positively contributed to the both measured inequalities in PWRPA

228 and PLTPA. Staff living in urban areas have different occupations in the university. The results of

229 our study show that office workers and medical staff who have the higher levels of PWRPA and

230 were more likely to be from higher SES groups, constitute $78.6 \%$ of the total university staff.

231 However, most of the medical university staff in rural areas are primary health staff (Behvarz) who

232 work in health houses. The job of primary health staff is more physically demanded because it

233 requires a lot of work outside the health houses in the village. [48] These results implies that staff

234 who live in urban areas were less physically active in their work place than their rural counterparts.

235 As it is explained before, difference in PA environment and social and cultural factors could be

236 the main reasons for the less PLTPA among urban resident staff compared to their rural

237 counterparts.

238 Our study indicated that SES was accounted for about one-fifth (19.9\%) and more than half $239(53.4 \%)$ of the measured socioeconomic inequality in WRPPA and PLTPA, respectively. Staff 240 from the higher socioeconomic groups usually work in jobs that require less PA due to their higher 241 education, more work experience or a more stable job position. Similar results was also seen in 242 other studies. [7, 11, 25] In this regard, having less physically demanded jobs could be the reason 243 for more PWRPA among staff from higher socioeconomic strata. Results of our study for PLTPA 244 was quite different; lower SES staff were more probable to have more PLTPA compared to their 245 higher SES counterparts. This result is in line with the results of a systematic review conducted by 246 Kirk MA and Rhodes. [12] Due to their higher demanded activity jobs, these staff usually do most 
247 of their daily physical activities in the workplace. [10] Therefore, they have less energy to do PA

248 in their leisure time. In addition, many leisure time activities involve monetary costs that these 249 individuals may not be able to afford. [49, 50] Additionally, lower SES staff may live in rural areas 250 and urban neighborhoods in which access to recreational and other facilities, their quality, and 251 social and cultural factors could decrease their tendency to engage in leisure time PA compared to 252 higher SES groups. The role of these factors in individuals' decisions about PA in their leisure time 253 has been well documented in the literature. [40-42, 45]

254 SSS is another factor which positively contributed to the measured inequality in PWRPA. In our 255 study, the prevalence of PPA was different among staff from different social strata. It seems that 256 social norms, values and beliefs towards PA among higher SES staff has led them to be less active 257 in work place than lower SES staff. Moreover, the results of our study indicated that shift work 258 jobs positively contributed to the more concentration of PWRPA among high SES staff by $12.6 \%$. 259 Shift worker staff were less likely to have occupational PPA than their non-shift worker 260 counterparts. This finding is in line with the results of previous studies. [51-53] Staff, who were 261 shift-worker, often have more physically demanded jobs such as medical and technical and service 262 jobs. Findings of the study showed that percentage of PWRPA among medical and 263 technical/service staff was $40.2 \%$ and $37.5 \%$, respectively, which was much lower than that of 264 office workers (77.2\%). Since shift-workers were more from lower socioeconomic groups, more 265 PA related to shift work has reduced PWRPA among lower SES staff rather than their higher SES 266 counterparts.

267 Furthermore, we found that higher likelihood of PLTPA among female staff increased its 268 concentration among lower SES staff by 19.5\%. In consistence with the findings of other studies, $269[54,55]$ the results of our study suggested that female participants were more likely to have PLTPA 
270 than their male counterparts. The reasons have pointed out in our study for women's PPA in Iran,

271 can be also applied to justify their higher PLTPA. It seems that employed female from lower

272 socioeconomic strata were more probable to encounter with inhibitors of leisure-time PA than their

273 higher SES counterparts. Marital status was another factor which was contributed to the measured

274 inequality in PLTPA by 36.2\%. Married staff were more likely to have PLTPA than staff without

275 spouse (divorced/widowed and single staff). This finding is in line with the results of other studies.

$276[56,57]$ More requirements of married life and associated economic problems to meet them could

277 be the reasons for more PLTPA of married staff from lower socioeconomic groups.

278 This is the first study which investigated socioeconomic inequalities in PPA and all its domains

279 among medical sciences university staff. To do this, we used a composite measure of staff's living

280 standards, education and occupational characteristics as the SES indicator. The findings of this

281 study provide new evidence of the current status of inequalities in PPA of employees and its

282 contributing factors which can be used to design targeted interventions to reduce these inequalities

283 in future. However, this study is subject to some limitations. First, in decomposition analysis,

$28443.5 \%$ of the measured socioeconomic inequality in PPA was explained by the study explanatory

285 variables. However, presence of the main contributors which have either positive or negative

286 contributions to the PPA inequality, provides sufficient evidence to reduce inequality in staff PPA.

287 Second, because to the use of cross-sectional level data from SHAHWAR cohort study, casual 288 interpretations should be done with caution.

289 Conclusions

290 While PTPA and PWRPA were more prevalent among staff from higher socioeconomic groups,

291 PLTPA was found more frequently among staff with lower SES. Health promotion programs in 
292 workplace should address both the goals of reducing the socioeconomic inequality of PTPA as a

293 whole and reduction of PPA in staff's workplace and leisure time.

294 Abbreviations

295 CC: Concentration Curve

296 CI: Concentration Index

297 IPAQ: International Physical Activity Questionnaire

298 METs: Metabolic Equivalent Rates

299 MoHME: Ministry of Health and Medical Education

300 PA: Physical Activity

301 PCA: Principal Component Analysis

302 PDGA: Poor Domestic and Gardening Activities

303 PLTPA: Poor Leisure-time Physical Activity

304 PPA: Poor Physical Activity

305 PTPA: Poor Total Physical Activity

306 PTRPA: Poor Transport-related Physical Activity

307 PWRPA: Poor work-related Physical Activity

308 SES: Socioeconomic Status

309 SHMU: Shahroud University of Medical Sciences

310 SHAHWAR: SHAhroud Healthcare Workers Associated Research

311 SSS: Subjective Social Status

312 Declarations

313 Ethics approval and consent to participate

314 The SHAHWAR cohort study was approved by the Ethics Committee of Shahroud University of 315 Medical Sciences (IR.SHMU.REC.1397.033) and the study data was collected after obtaining 316 informed consent.

\section{Consent for publication}

318 Not applicable. 
320 The datasets used and/or analyzed during the current study are available from the corresponding 321 author on reasonable request.

\section{Competing interests}

323 The authors declare that they have no competing interests.

\section{Funding}

325 This work was supported by Iran's Ministry of Health and Medical Education (MoHME) and 326 Shahroud University of Medical Sciences (SHMU) [Grant No. 9738].

\section{Authors' contributions}

328 SM. M., F. Z., and F. S. contributed to the data gathering of the cohort study. M. Kh., SM. M., and 329 F. Z. designed and performed data analysis, SM. M., M. Kh., and F. S. contributed to drafting the 330 manuscript, and all authors contributed to the conceiving the original idea of the manuscript and 331 interpretation of the results. They also have read and approved the final version of the manuscript.

\section{Acknowledgements}

333 We would like to thank the managers and staff of SHAHWAR Cohort Study, for helping us to 334 conduct this study.

\section{References}

336 1. Lee I-M, Shiroma EJ, Lobelo F, Puska P, Blair SN, Katzmarzyk PT, Group LPASW: Effect of physical 337 inactivity on major non-communicable diseases worldwide: an analysis of burden of disease and life expectancy. The lancet 2012, 380(9838):219-229.

339 2. Kim YS, Park YS, Allegrante JP, Marks R, Ok H, Cho KO, Garber CE: Relationship between

3. Puig-Ribera A, Martínez-Lemos I, Giné-Garriga M, González-Suárez ÁM, Bort-Roig J, Fortuño J, Muñoz-Ortiz L, McKenna J, Gilson ND: Self-reported sitting time and physical activity: 
interactive associations with mental well-being and productivity in office employees. $B M C$ public health 2015, 15(1):1-10.

4. van Scheppingen AR, de Vroome EM, ten Have KC, Zwetsloot GI, Bos EH, van Mechelen W: Motivations for health and their associations with lifestyle, work style, health, vitality, and employee productivity. J Occup Environ Med 2014, 56(5):540-546.

5. Losina E, Yang HY, Deshpande BR, Katz JN, Collins JE: Physical activity and unplanned illness-

6. Wang F, McDonald T, Champagne L, Edington DW: Relationship of body mass index and physical activity to health care costs among employees. J Occup Environ Med 2004, 46(5):428436.

7. Abu Saad H, Low PK, Jamaluddin R, Chee HP: Level of Physical Activity and Its Associated

8. Humphreys BR, Ruseski JE: Economic determinants of participation in physical activity and sport. Unpublished Working Paper Series 2006(06-13):1-25.

9. Bjørkelund OA, Degerud H, Bere E: Socio-demographic, personal, environmental and

10. Beenackers MA, Kamphuis CB, Giskes K, Brug J, Kunst AE, Burdorf A, Van Lenthe FJ: Socioeconomic inequalities in occupational, leisure-time, and transport related physical 
12. Kirk MA, Rhodes RE: Occupation Correlates of Adults' Participation in Leisure-Time Physical Activity: A Systematic Review. Am J Prev Med 2011, 40(4):476-485.

13. Fetherman DL, McGrane TG, Cebrick-Grossman JJWH, Safety: Health Promotion for Small Workplaces: A Community-Based Participatory Research Partnership. 2021, 69(1):7-14.

371 14. Van Kirk MLWH, Safety: Employee Wellness Pilot Program. 2020:2165079920976522.

372 15. Pronk NP: Physical activity promotion in business and industry: evidence, context, and recommendations for a national plan. JPAH 2009, 6(s2):S220-S235.

374 16. Moradi G, Mostafavi F, Piroozi B, Zareie B, Mahboobi M, Rasouli MA: The prevalence of physical 375 inactivity in Iranian adolescents and the impact of economic and social inequalities on it: results of a National Study in 2018. BMC public health 2020, 20(1):1-9.

377 17. Mosallanezhad Z, Sotoudeh GR, Jutengren G, Salavati M, Harms-Ringdahl K, Wikmar LN, Frändin 378

18. Karyani AK, Matin BK, Soltani S, Rezaei S, Soofi M, Salimi Y, Moradinazar M, Hajizadeh M, Pasdar

20. Vyas S, Kumaranayake L: Constructing socio-economic status indices: how to use principal 
21. O'donnell O, Van Doorslaer E, Wagstaff A, Lindelow M: Analyzing health equity using household survey data: a guide to techniques and their implementation: The World Bank; 2007.

392 22. Wagstaff A: The bounds of the concentration index when the variable of interest is binary, with an application to immunization inequality. Health Econ 2005, 14(4):429-432.

394 23. Wagstaff A, Doorslaer vE, Watanabe N: On decomposing the causes of health sector 395 inequalities with an application to malnutrition inequalities in Vietnam: The World Bank; 2001.

396 24. StataCorp. 2015. Stata Statistical Software: Release 14. College Station, TX: StataCorp LP.

397 25. Vandelanotte C, Short C, Rockloff M, Di Millia L, Ronan K, Happell B, Duncan MJ, Health: How do 398 different occupational factors influence total, occupational, and leisure-time physical activity? JPAH 2015, 12(2):200-207.

400 26. Cerin E, Leslie E: How socio-economic status contributes to participation in leisure-time 401 physical activity. Soc Sci Med 2008, 66(12):2596-2609.

402 27. Kamphuis CB, van Lenthe FJ, Giskes K, Brug J, Mackenbach JP, place: Perceived environmental determinants of physical activity and fruit and vegetable consumption among high and low socioeconomic groups in the Netherlands. Health Place 2007, 13(2):493-503.

405 28. Humphreys BR, Ruseski JE: Participation in physical activity and government spending on parks 406

407 29. Brown H, Roberts J: Exercising choice: the economic determinants of physical activity 408 behaviour of an employed population. Soc Sci Med 2011, 73(3):383-390.

409 30. Tewahade S, Li K, Goldstein RB, Haynie D, lannotti RJ, Simons-Morton B, Health: Association between the built environment and active transportation among US adolescents. J Transp Health 2019, 15:100629.

412 31. Steinmetz-Wood M, Kestens Y: Does the effect of walkable built environments vary by neighborhood socioeconomic status? Prev Med 2015, 81:262-267. 
414 32. Frerichs L, Huang TT-K, Chen D-R: Associations of subjective social status with physical activity and body mass index across four Asian countries. Journal of obesity 2014, 2014.

416 33. Ball K, Jeffery RW, Abbott G, McNaughton SA, Crawford D: Is healthy behavior contagious:

34. Emmons KM, Barbeau EM, Gutheil C, Stryker JE, Stoddard AM: Social influences, social context,

35. Zamani Sani SH, Eskandarnejad M, Fathirezaie Z: Body image, perceived physical fitness, physical activity, body mass index and age in women. WHB 2016, 3(3):1-5.

424 36. Sadrollahi A, Hosseinian M, Alavi NM, Khalili Z, Esalatmanesh S: Physical activity patterns in the

37. Jamil AT, Ismail A, Idris IB, Soo KC, Teng AJ, Bahaman NA, Fadzil MF: Levels of physical activity and its associated factors among health care workers. Malaysian J Public Health Med

429 38. Arab-Moghaddam N, Henderson KA, Sheikholeslami R: Women's leisure and constraints to

39. Bauman A, Ma G, Cuevas F, Omar Z, Waqanivalu T, Phongsavan P, Keke K, Bhushan A, Equity, Group N-cDRFPC: Cross-national comparisons of socioeconomic differences in the prevalence of leisure-time and occupational physical activity, and active commuting in six Asia-Pacific countries. JECH 2011, 65(1):35-43.

40. Hino AA, Reis RS, Sarmiento OL, Parra DC, Brownson RC: The built environment and recreational physical activity among adults in Curitiba, Brazil. Prev Med 2011, 52(6):419-422. 
437 41. Cranney L, Phongsavan P, Kariuki M, Stride V, Scott A, Hua M, Bauman A: Impact of an outdoor gym on park users' physical activity: A natural experiment. Health Place 2016, 37:26-34.

42. Giles-Corti B, Donovan RJ: Socioeconomic status differences in recreational physical activity

43. Hull A, O’Holleran C: Bicycle infrastructure: can good design encourage cycling? Urban, Planning and Transport Research 2014, 2(1):369-406.

44. Kaczynski AT, Henderson KA: Environmental correlates of physical activity: a review of

45. Ross CE: Walking, exercising, and smoking: does neighborhood matter? Soc Sci Med 2000,

46. Holtermann A, Hansen J, Burr H, Søgaard K, Sjøgaard G: The health paradox of occupational and

47. Dosemeci M, Hayes RB, Vetter R, Hoover RN, Tucker M, Engin K, Unsal M, Blair A: Occupational physical activity, socioeconomic status, and risks of 15 cancer sites in Turkey. Cancer Causes

48. Javanparast S, Baum F, Labonte R, Sanders D: Community health workers' perspectives on their contribution to rural health and well-being in Iran. Am J Public Health 2011, 101(12):22872292.

456 49. Chinn DJ, White M, Harland J, Drinkwater C, Raybould S: Barriers to physical activity and socioeconomic position: implications for health promotion. JECH 1999, 53(3):191. 


9

1

51. Ma CC, Burchfiel CM, Fekedulegn D, Andrew ME, Charles LE, Gu JK, Mnatsakanova A, Violanti JM: Association of shift work with physical activity among police officers: the Buffalo cardiometabolic occupational police stress study. J Occup Environ Med 2011, 53(9):1030-1036.

52. Salmon J, Owen N, Bauman A, Schmitz MKH, Booth M: Leisure-time, occupational, and household physical activity among professional, skilled, and less-skilled workers and homemakers. Prev Med 2000, 30(3):191-199.

53. Burton NW, Turrell G: Occupation, hours worked, and leisure-time physical activity. Prev Med 2000, 31(6):673-681.

54. Talaei M, Rabiei K, Talaei Z, Amiri N, Zolfaghari B, Kabiri P, Sarrafzadegan N: Physical activity, sex, and socioeconomic status: A population based study. ARYA Atheroscler 2013, 9(1):51.

55. Mota J, Esculcas C: Leisure-time physical activity behavior: structured and unstructured choices according to sex, age, and level of physical activity. Int J Behav Med 2002, 9(2):111-121.

56. Pitsavos C, Panagiotakos DB, Lentzas Y, Stefanadis C: Epidemiology of leisure-time physical activity in socio-demographic, lifestyle and psychological characteristics of men and women in Greece: the ATTICA Study. BMC public health 2005, 5(1):1-9.

57. Schmitz K, French SA, Jeffery RW: Correlates of changes in leisure time physical activity over 2 years: the Healthy Worker Project. Prev Med 1997, 26(4):570-579.

0


Table1. Descriptive statistics for staff of Medical Sciences University by all types of PPA status in Shahroud, Iran

\begin{tabular}{|c|c|c|c|c|c|c|}
\hline Characteristics & $\begin{array}{l}\text { Total } \\
\text { N }(\%)\end{array}$ & $\begin{array}{c}\text { PLTPA }^{\dagger} \\
\text { N }(\%)\end{array}$ & $\begin{array}{l}\text { PDGA }^{\dagger} \\
\text { N }(\%)\end{array}$ & $\begin{array}{c}\text { PWRPA }^{\dagger} \\
\text { N }(\%)\end{array}$ & $\begin{array}{c}\text { PTRPA }^{\dagger} \\
\text { N }(\%)\end{array}$ & $\begin{array}{l}\text { PTPA }^{\dagger} \\
\text { N }(\%)\end{array}$ \\
\hline \multicolumn{7}{|l|}{ Gender } \\
\hline Male & $468(40.45)$ & $182(38.89)$ & $276(58.97)$ & $246(52.56)$ & $183(39.10)$ & $212(45.30)$ \\
\hline Female & $689(59.55)$ & $394(57.18)$ & $242(35.12)$ & $332(48.19)$ & $395(57.33)$ & $366(53.12)$ \\
\hline \multicolumn{7}{|l|}{ Age } \\
\hline $20-29$ & $108(9.33)$ & $57(52.78)$ & $67(62.04)$ & $40(37.04)$ & $48(44.44)$ & $43(39.81)$ \\
\hline $30-39$ & $532(45.98)$ & $272(51.13)$ & $207(38.91)$ & $260(48.87)$ & $258(48.50)$ & $251(47.18)$ \\
\hline $40-49$ & $378(32.67)$ & $177(46.83)$ & $173(45.77)$ & $204(53.97)$ & $195(51.59)$ & 204 (53.97) \\
\hline$>=50$ & $139(87.99)$ & $70(50.36)$ & $71(51.08)$ & $74(53.24)$ & $77(55.40)$ & $80(57.55)$ \\
\hline \multicolumn{7}{|l|}{ Household size } \\
\hline$<=2$ & 185 (15.99) & $87(47.03)$ & $105(56.76)$ & $94(50.81)$ & $96(51.89)$ & $95(51.35)$ \\
\hline $3-4$ & $850(73.47)$ & $424(50.00)$ & $354(41.65)$ & $429(50.47)$ & $420(49.41)$ & $425(50.00)$ \\
\hline$>=5$ & $122(10.54)$ & $64(52.46)$ & $59(48.36)$ & $55(45.08)$ & $62(50.82)$ & $58(47.54)$ \\
\hline \multicolumn{7}{|l|}{ Marital status } \\
\hline Single & $88(7.61)$ & $28(31.82)$ & $57(64.77)$ & $44(50.00)$ & $48(54.55)$ & $45(51.14)$ \\
\hline Married & $1011(83.38)$ & $521(51.53)$ & $435(43.03)$ & $511(50.54)$ & $498(49.26)$ & $516(51.04)$ \\
\hline Divorced/Widowed & $58(5.01)$ & $27(46.55)$ & $26(44.83)$ & $23(39.66)$ & $32(55.17)$ & $17(29.31)$ \\
\hline \multicolumn{7}{|l|}{ Job } \\
\hline Office worker staff & $324(28)$ & $139(42.90)$ & $140(43.21)$ & $250(77.16)$ & $155(47.84)$ & $220(67.90)$ \\
\hline Medical staff & $585(50.56)$ & $304(51.97)$ & $250(42.74)$ & $235(40.17)$ & $311(53.16)$ & $268(45.81)$ \\
\hline $\begin{array}{l}\text { Technical and service } \\
\text { staff }\end{array}$ & $248(21.43)$ & $133(53.63)$ & $128(51.61)$ & $93(37.50)$ & $112(45.16)$ & $90(36.29)$ \\
\hline \multicolumn{7}{|l|}{ Having secondary job } \\
\hline Yes & $200(17.29)$ & $75(37.50)$ & $93(46.50)$ & $101(50.50)$ & $78(39.00)$ & $90(45.00)$ \\
\hline
\end{tabular}




\begin{tabular}{|c|c|c|c|c|c|c|}
\hline No & $957(82.71)$ & $501(52.35)$ & $425(44.41)$ & 477 (49.84) & $500(52.25)$ & $488(50.99)$ \\
\hline \multicolumn{7}{|l|}{ shift work } \\
\hline Yes & $484(41.83)$ & $275(53.10)$ & 225 (46.49) & $161(33.26)$ & $232(47.93)$ & $171(35.33)$ \\
\hline No & $673(58.17)$ & $319(47.40)$ & $293(43.54)$ & 417 (61.96) & $346(51.41)$ & $407(60.48)$ \\
\hline \multicolumn{7}{|l|}{ Socioeconomic status } \\
\hline 1st quintile (lowest) & $232(20.05)$ & $135(58.19)$ & $116(50.00)$ & $90(38.79)$ & $121(52.16)$ & $95(40.95)$ \\
\hline 2nd quintile & $231(19.97)$ & $128(55.41)$ & $100(43.29)$ & $120(51.95)$ & $115(49.78)$ & $119(51.52)$ \\
\hline 3rd quintile & $232(20.05)$ & $123(53.02)$ & $88(37.93)$ & $112(48.28)$ & $125(53.88)$ & $122(52.59)$ \\
\hline 4th quintile & $231(19.97)$ & $112(48.48)$ & $106(45.89)$ & $121(52.38)$ & $112(48.48)$ & $116(50.22)$ \\
\hline 5th quintile (highest) & $231(19.97)$ & $78(33.77)$ & $108(46.75)$ & $135(58.44)$ & $105(45.45)$ & $126(54.55)$ \\
\hline \multicolumn{7}{|c|}{ Subjective social status } \\
\hline Lowest & $35(3.03)$ & $16(45.71)$ & $17(48.57)$ & $21(60.00)$ & $17(48.57)$ & $18(51.43)$ \\
\hline Low & $384(33.19)$ & $110(44.53)$ & $101(40.89)$ & $132(53.44)$ & $124(50.20)$ & $119(48.18)$ \\
\hline Medium & $660(57.04)$ & $335(52.43)$ & $294(46.01)$ & $313(48.98)$ & $325(50.86)$ & $327(51.17)$ \\
\hline Higher & $67(5.79)$ & $87(47.54)$ & $82(44.81)$ & $89(48.63)$ & $90(49.18)$ & $92(50.27)$ \\
\hline Highest & $11(0.95)$ & $28(52.83)$ & $24(45.28)$ & $23(43.40)$ & $22(41.51)$ & $22(41.51)$ \\
\hline \multicolumn{7}{|l|}{ Using car } \\
\hline Yes & $631(54.54)$ & $288(45.64)$ & $289(45.80)$ & $318(50.40)$ & $289(45.80)$ & $310(49.13)$ \\
\hline No & $526(45.46)$ & $288(54.75)$ & $229(43.54)$ & $260(49.43)$ & $289(54.94)$ & $268(50.95)$ \\
\hline \multicolumn{7}{|l|}{ Having PLTPA } \\
\hline Yes & 576 (49.78) & - & $246(42.71)$ & $283(49.13)$ & $299(51.91)$ & $326(56.60)$ \\
\hline No & $581(50.22)$ & - & $272(46.82)$ & $295(50.77)$ & $279(48.02)$ & $252(43.37)$ \\
\hline \multicolumn{7}{|l|}{ Having PDGA } \\
\hline Yes & $518(44.77)$ & $246(47.49)$ & - & $269(51.93)$ & $271(52.32)$ & $287(55.41)$ \\
\hline No & $639(55.23)$ & $330(51.64)$ & - & 309 (48.36) & 307 (48.04) & $291(45.54)$ \\
\hline Having PTRPA & & & & & & \\
\hline
\end{tabular}




\begin{tabular}{|l|c|c|c|c|c|c|}
\cline { 2 - 6 } Yes & $578(49.96)$ & $299(51.73)$ & $271(46.89)$ & $301(52.08)$ & - & $385(66.61)$ \\
\hline No & $579(50.04)$ & $277(47.84)$ & $247(42.66)$ & $277(47.84)$ & - & $193(33.33)$ \\
\hline Having PWRPA & $578(49.96)$ & $283(48.96)$ & $269(46.54)$ & - & $301(52.08)$ & $459(79.41)$ \\
\hline Yes & $579(50.04)$ & $293(50.60)$ & $249(43.01)$ & - & $277(52.08)$ & $119(20.55)$ \\
\hline No & & & & & \\
\hline
\end{tabular}

${ }^{\dagger}$ Abbreviations; PLTPA: poor leisure time PA, PDGA: poor domestic and gardening activities, PWRPA: poor work-related PA, PTRPA: poor transport-related PA, PTPA: poor total PA

\section{Table 2. Concentration indices for all types of PPA among staff of Medical Sciences}

\section{University in Shahroud, Iran}

\begin{tabular}{|lccc|}
\hline Types of PPA $^{\dagger}$ & $\begin{array}{c}\text { Wagstaff normalized } \\
\text { concentration index }\end{array}$ & $\begin{array}{c}\text { Robust standard error } \\
\text { p-value }\end{array}$ \\
\hline PLTPA $^{\dagger}$ & -0.191 & 0.034 & $<0.01$ \\
\hline PDGA $^{\dagger}$ & -0.021 & 0.034 & 0.53 \\
\hline PWRPA $^{\dagger}$ & 0.141 & 0.034 & $<0.01$ \\
\hline PTRPA $^{\dagger}$ & -0.059 & 0.034 & 0.08 \\
\hline PTPA $^{\dagger}$ & 0.092 & & $<0.01$ \\
\hline
\end{tabular}


†Abbreviations; PPA: PPA, PLTPA: poor leisure time PA, PDGA: poor domestic and gardening activities, PWRPA: poor workrelated PA, PTRPA: poor transport-related PA, PTPA: poor total PA

491 
Table 3. Decomposition of socioeconomic inequalities in all types of PPA among staff of Medical Sciences University in Shahroud, Iran

\begin{tabular}{|c|c|c|c|c|c|c|c|c|c|c|c|c|c|c|c|c|}
\hline \multirow{2}{*}{ Characteristics } & \multicolumn{3}{|c|}{ Marginal effect } & \multicolumn{3}{|c|}{ Elasticity } & \multirow{2}{*}{$\mathbf{C}_{\mathbf{k}}$} & \multicolumn{3}{|c|}{ Absolute contribution to CI } & \multicolumn{3}{|c|}{ Relative Contribution } & \multicolumn{3}{|c|}{ \% Contribution } \\
\hline & PTPA & PLTPA & PWRPA & PTPA & PLTPA & PWRPA & & PTPA & PLTPA & \begin{tabular}{|l|} 
PWRPA \\
\end{tabular} & PTPA & PLTPA & PWRPA & PTPA & PLTPA & PWRPA \\
\hline \multicolumn{17}{|l|}{ Gender } \\
\hline Male & 0.000 & 0.000 & 0.000 & 0.000 & 0.000 & 0.000 & -0.205 & 0.010 & 0.000 & 0.000 & 0.000 & 0.000 & 0.000 & 0.00 & 0.00 & 0.00 \\
\hline Female & $0.062^{*}$ & $0.223^{*}$ & $-0.076^{*}$ & 0.074 & 0.267 & -0.091 & 0.205 & 0.015 & 0.055 & -0.019 & 0.166 & -0.287 & -0.133 & 16.55 & -28.71 & -13.31 \\
\hline Sum & & & & & & & & 0.025 & 0.055 & -0.019 & 0.166 & -0.287 & -0.133 & 16.55 & -28.71 & -13.31 \\
\hline \multicolumn{17}{|l|}{ Age } \\
\hline $20-29$ & 0.000 & 0.000 & 0.000 & 0.000 & 0.000 & 0.000 & 0.205 & 0.000 & 0.000 & 0.000 & 0.000 & 0.000 & 0.000 & 0.00 & 0.00 & 0.00 \\
\hline $30-39$ & 0.092 & $\begin{array}{l}-0.049 \\
\end{array}$ & 0.049 & 0.022 & -0.045 & 0.045 & 0.072 & 0.002 & -0.003 & 0.003 & 0.017 & 0.017 & 0.023 & 1.74 & 1.69 & 2.29 \\
\hline $40-49$ & 0.065 & -0.088 & 0.078 & 0.042 & -0.058 & 0.051 & -0.104 & -0.004 & 0.006 & -0.005 & -0.048 & -0.031 & -0.038 & -4.83 & -3.14 & -3.79 \\
\hline$>=50$ & 0.092 & -0.018 & 0.052 & 0.022 & -0.004 & 0.012 & -0.116 & -0.003 & 0.001 & -0.001 & $\begin{array}{c}-0.028 \\
\end{array}$ & -0.003 & -0.010 & -2.80 & -0.27 & -1.03 \\
\hline Sum & & & & & & & & -0.005 & 0.003 & -0.004 & -0.059 & -0.017 & -0.025 & -5.89 & $\begin{array}{l}-1.72 \\
\end{array}$ & -2.53 \\
\hline \multicolumn{17}{|l|}{ Household size } \\
\hline$<=2$ & 0.000 & 0.000 & 0.000 & 0.000 & 0.000 & 0.000 & 0.346 & 0.000 & 0.000 & 0.000 & 0.000 & 0.000 & 0.000 & 0.00 & 0.00 & 0.00 \\
\hline
\end{tabular}


Table 3. Decomposition of socioeconomic inequalities in all types of PPA among staff of Medical Sciences University in Shahroud, Iran

\begin{tabular}{|c|c|c|c|c|c|c|c|c|c|c|c|c|c|c|c|c|}
\hline \multirow{2}{*}{ Characteristics } & \multicolumn{3}{|c|}{ Marginal effect } & \multicolumn{3}{|c|}{ Elasticity } & \multirow{2}{*}{$\mathbf{C}_{\mathrm{k}}$} & \multicolumn{3}{|c|}{ Absolute contribution to CI } & \multicolumn{3}{|c|}{ Relative Contribution } & \multicolumn{3}{|c|}{$\%$ Contribution } \\
\hline & PTPA & PLTPA & PWRPA & PTPA & PLTPA & PWRPA & & PTPA & PLTPA & PWRPA & PTPA & PLTPA & PWRPA & PTPA & PLTPA & PWRPA \\
\hline 3 to 4 & -0.007 & -0.023 & -0.027 & -0.010 & -0.034 & -0.039 & -0.053 & 0.001 & 0.002 & 0.002 & 0.006 & -0.010 & 0.015 & 0.59 & -0.95 & 1.48 \\
\hline$>=5$ & -0.021 & 0.010 & -0.091 & -0.005 & 0.002 & -0.019 & -0.383 & 0.002 & -0.001 & 0.007 & 0.019 & 0.004 & 0.053 & 1.89 & 0.43 & 5.26 \\
\hline Sum & & & & & & & & 0.002 & 0.001 & 0.009 & 0.025 & -0.005 & 0.067 & 2.48 & -0.52 & 6.73 \\
\hline Marital status & & & & & & & & & & & & & & & & \\
\hline Single & 0.000 & 0.000 & 0.000 & 0.000 & 0.000 & 0.000 & 0.411 & 0.000 & 0.000 & 0.000 & 0.000 & 0.000 & 0.000 & 0.00 & 0.00 & 0.00 \\
\hline Married & -0.012 & $0.181^{*}$ & -0.023 & -0.021 & 0.317 & -0.040 & -0.217 & 0.004 & -0.069 & 0.009 & 0.049 & 0.361 & 0.061 & 4.89 & 36.08 & 6.13 \\
\hline Divorced/Widowed & $-0.189^{*}$ & 0.023 & -0.107 & -0.019 & 0.002 & -0.011 & -0.102 & 0.002 & 0.000 & 0.001 & 0.021 & 0.001 & 0.008 & 2.12 & 0.12 & 0.78 \\
\hline Sum & & & & & & & & 0.006 & -0.069 & 0.010 & 0.070 & 0.362 & 0.069 & 7.001 & 36.20 & 6.91 \\
\hline Place of residence & & & & & & & & & & & & & & & & \\
\hline Rural & 0.000 & 0.000 & 0.000 & 0.000 & 0.000 & 0.000 & -0.399 & 0.000 & 0.000 & 0.000 & 0.000 & 0.000 & 0.000 & 0.00 & 0.00 & 0.00 \\
\hline Urban & $-0.081^{*}$ & -0.062 & 0.055 & -0.147 & -0.113 & 0.100 & 0.399 & -0.059 & -0.045 & 0.040 & -0.640 & 0.235 & 0.284 & -63.98 & 23.47 & 28.38 \\
\hline Sum & & & & & & & & -0.06 & -0.045 & 0.010 & -0.640 & 0.23 & 0.28 & -63.98 & 23.47 & 28.38 \\
\hline Job & & & & & & & & & & & & & & & & \\
\hline Office worker & 0.000 & 0.000 & 0.000 & 0.000 & 0.000 & 0.000 & 0.292 & 0.000 & 0.000 & 0.000 & 0.000 & 0.000 & 0.000 & 0.00 & 0.00 & 0.00 \\
\hline Medical staff & -0.036 & 0.041 & $-0.272^{*}$ & -0.036 & 0.042 & -0.275 & 0.271 & -0.010 & 0.011 & -0.075 & -0.107 & -0.059 & -0.531 & -10.70 & -5.91 & -53.13 \\
\hline $\begin{array}{l}\text { Technical and } \\
\text { service staff }\end{array}$ & -0.041 & 0.070 & $-0.258^{*}$ & -0.018 & 0.030 & -0.111 & -0.752 & 0.013 & -0.023 & 0.083 & 0.145 & 0.118 & 0.592 & 14.54 & 11.81 & 59.18 \\
\hline
\end{tabular}


Table 3. Decomposition of socioeconomic inequalities in all types of PPA among staff of Medical Sciences University in Shahroud, Iran

\begin{tabular}{|c|c|c|c|c|c|c|c|c|c|c|c|c|c|c|c|c|}
\hline \multirow{2}{*}{ Characteristics } & \multicolumn{3}{|c|}{ Marginal effect } & \multicolumn{3}{|c|}{ Elasticity } & \multirow{2}{*}{$\mathbf{C}_{\mathrm{k}}$} & \multicolumn{3}{|c|}{ Absolute contribution to CI } & \multicolumn{3}{|c|}{ Relative Contribution } & \multicolumn{3}{|c|}{$\%$ Contribution } \\
\hline & PTPA & PLTPA & PWRPA & PTPA & PLTPA & PWRPA & & PTPA & PLTPA & PWRPA & PTPA & PLTPA & PWRPA & PTPA & PLTPA & PWRPA \\
\hline Sum & & & & & & & & 0.004 & -0.011 & 0.008 & 0.038 & 0.059 & 0.060 & 3.84 & 5.90 & 6.05 \\
\hline \multirow{2}{*}{\multicolumn{17}{|c|}{$\begin{array}{l}\text { Having secondary } \\
\text { job }\end{array}$}} \\
\hline & & & & & & & & & & & & & & & & \\
\hline No & 0.000 & 0.000 & 0.000 & 0.000 & 0.000 & -0.003 & 0.000 & 0.000 & 0.000 & 0.000 & 0.000 & 0.000 & 0.000 & 0.00 & 0.00 & 0.00 \\
\hline Yes & -0.005 & -0.058 & -0.007 & -0.002 & -0.020 & -0.002 & 0.144 & 0.000 & -0.003 & 0.000 & -0.003 & 0.015 & -0.002 & -0.26 & 1.53 & 0.00 \\
\hline Sum & & & & & & & & 0.000 & -0.003 & 0.000 & -0.003 & 0.015 & -0.002 & -0.26 & 1.53 & 0.00 \\
\hline \multicolumn{17}{|l|}{ Shift work } \\
\hline No & 0.000 & 0.000 & 0.000 & 0.000 & 0.000 & 0.000 & 0.135 & 0.000 & 0.000 & 0.000 & 0.000 & 0.000 & 0.000 & 0.00 & 0.00 & 0.00 \\
\hline Yes & -0.044 & 0.034 & $-0.157^{*}$ & -0.037 & 0.029 & -0.131 & -0.135 & 0.005 & -0.004 & 0.018 & 0.055 & 0.020 & 0.126 & 5.46 & 2.02 & 12.65 \\
\hline Sum & & & & & & & & 0.005 & -0.007 & 0.018 & 0.055 & 0.020 & 0.126 & 5.46 & 2.02 & 12.65 \\
\hline \multicolumn{17}{|l|}{ Objective SES } \\
\hline 1st quintile (lowest) & 0.000 & 0.000 & 0.000 & 0.000 & 0.000 & 0.000 & -1.000 & 0.000 & 0.000 & 0.000 & 0.000 & 0.000 & 0.000 & 0.00 & 0.00 & 0.00 \\
\hline 2nd quintile & 0.052 & -0.028 & 0.083 & 0.021 & -0.011 & 0.033 & -0.499 & -0.010 & 0.006 & -0.017 & -0.112 & -0.029 & -0.118 & -11.22 & -2.88 & -11.78 \\
\hline 3rd quintile & 0.067 & -0.067 & 0.057 & 0.027 & -0.027 & 0.023 & 0.001 & 0.000 & 0.000 & 0.000 & 0.000 & 0.000 & 0.000 & 0.03 & 0.02 & 0.02 \\
\hline 4th quintile & 0.029 & -0.095 & 0.047 & 0.011 & -0.038 & 0.019 & 0.501 & 0.006 & -0.019 & 0.009 & 0.063 & 0.100 & 0.068 & 6.27 & 10.01 & 6.76 \\
\hline $\begin{array}{l}\text { 5th quintile } \\
\text { (highest) }\end{array}$ & 0.054 & $-0.220^{*}$ & 0.088 & 0.022 & -0.088 & 0.035 & 1.000 & 0.022 & -0.088 & 0.035 & 0.235 & 0.462 & 0.249 & 23.52 & 46.23 & 24.95 \\
\hline Sum & & & & & & & & 0.017 & -0.102 & 0.028 & 0.186 & 0.534 & 0.199 & 18.61 & 53.38 & 19.95 \\
\hline
\end{tabular}


Table 3. Decomposition of socioeconomic inequalities in all types of PPA among staff of Medical Sciences University in Shahroud, Iran

\begin{tabular}{|c|c|c|c|c|c|c|c|c|c|c|c|c|c|c|c|c|}
\hline \multirow{2}{*}{ Characteristics } & \multicolumn{3}{|c|}{ Marginal effect } & \multicolumn{3}{|c|}{ Elasticity } & \multirow{2}{*}{$\mathbf{C}_{\mathrm{k}}$} & \multicolumn{3}{|c|}{ Absolute contribution to CI } & \multicolumn{3}{|c|}{ Relative Contribution } & \multicolumn{3}{|c|}{$\%$ Contribution } \\
\hline & PTPA & PLTPA & PWRPA & PTPA & PLTPA & PWRPA & & PTPA & PLTPA & PWRPA & PTPA & PLTPA & PWRPA & PTPA & PLTPA & PWRPA \\
\hline \multirow{2}{*}{\multicolumn{17}{|c|}{$\begin{array}{l}\text { Subjective social } \\
\text { status }\end{array}$}} \\
\hline & & & & & & & & & & & & & & & & \\
\hline Lowest & 0.000 & 0.000 & 0.000 & 0.000 & 0.000 & 0.000 & -0.295 & 0.000 & 0.000 & 0.000 & 0.000 & 0.000 & 0.000 & 0.00 & 0.00 & 0.00 \\
\hline Low & $-0.384^{*}$ & -0.021 & -0.121 & -0.044 & -0.002 & -0.014 & -0.366 & 0.016 & 0.001 & 0.005 & 0.178 & -0.005 & 0.036 & 17.78 & -0.46 & 3.65 \\
\hline Medium & $-0.252^{*}$ & 0.015 & -0.065 & -0.288 & 0.018 & -0.074 & -0.307 & 0.088 & -0.005 & 0.023 & 0.965 & 0.028 & 0.161 & 96.51 & 2.85 & 16.14 \\
\hline Higher & -0.247 & -0.021 & -0.007 & -0.164 & -0.014 & -0.005 & 0.390 & -0.064 & -0.005 & -0.002 & -0.699 & 0.028 & -0.013 & -69.89 & 2.79 & -1.29 \\
\hline Highest & -0.246 & -0.023 & -0.192 & -0.015 & -0.001 & -0.012 & 0.395 & -0.006 & -0.001 & -0.005 & -0.064 & 0.003 & -0.033 & -6.41 & 0.29 & -3.26 \\
\hline Sum & & & & & & & & 0.035 & -0.010 & 0.021 & 0.380 & 0.055 & 0.152 & 37.99 & 5.46 & 15.24 \\
\hline \multicolumn{17}{|l|}{ Using car } \\
\hline No & 0.000 & 0.000 & 0.000 & 0.000 & 0.000 & 0.000 & -0.152 & 0.000 & 0.000 & 0.000 & 0.000 & 0.000 & 0.000 & 0.00 & 0.00 & 0.00 \\
\hline Yes & 0.019 & -0.017 & -0.027 & 0.020 & -0.019 & -0.029 & 0.152 & 0.003 & -0.003 & -0.004 & 0.034 & 0.015 & -0.031 & 3.40 & 1.51 & -3.14 \\
\hline Sum & & & & & & & & 0.003 & -0.003 & -0.004 & 0.034 & 0.015 & -0.031 & 3.40 & 1.51 & -3.14 \\
\hline \multicolumn{17}{|l|}{ Having PLTPA } \\
\hline No & 0.000 & - & 0.000 & 0.000 & - & 0.000 & 0.191 & 0.000 & - & 0.000 & 0.000 & - & 0.000 & 0.00 & - & 0.00 \\
\hline Yes & $0.130^{*}$ & - & 0.034 & 0.129 & - & 0.034 & -0.191 & -0.025 & - & -0.006 & -0.270 & - & -0.046 & -26.97 & - & -4.60 \\
\hline Sum & & & & & & & & -0.025 & - & -0.006 & -0.270 & - & -0.046 & -26.97 & - & -4.60 \\
\hline Having PDGA & & & & & & & & & & & & & & & & \\
\hline
\end{tabular}


Table 3. Decomposition of socioeconomic inequalities in all types of PPA among staff of Medical Sciences University in Shahroud, Iran

\begin{tabular}{|c|c|c|c|c|c|c|c|c|c|c|c|c|c|c|c|c|}
\hline \multirow{2}{*}{ Characteristics } & \multicolumn{3}{|c|}{ Marginal effect } & \multicolumn{3}{|c|}{ Elasticity } & \multirow{2}{*}{$\mathbf{C}_{\mathrm{k}}$} & \multicolumn{3}{|c|}{ Absolute contribution to CI } & \multicolumn{3}{|c|}{ Relative Contribution } & \multicolumn{3}{|c|}{$\%$ Contribution } \\
\hline & PTPA & PLTPA & PWRPA & PTPA & PLTPA & PWRPA & & PTPA & PLTPA & PWRPA & PTPA & PLTPA & PWRPA & PTPA & PLTPA & PWRPA \\
\hline No & 0.000 & 0.000 & 0.000 & 0.000 & 0.000 & 0.000 & 0.000 & 0.000 & 0.000 & 0.000 & 0.000 & 0.000 & 0.000 & 0.00 & 0.00 & 0.00 \\
\hline Yes & $0.092^{*}$ & 0.015 & 0.030 & 0.083 & 0.014 & 0.027 & -0.021 & -0.002 & 0.000 & -0.001 & -0.019 & 0.001 & -0.004 & -1.90 & 0.15 & -0.40 \\
\hline Sum & & & & & & & & -0.002 & 0.000 & -0.001 & -0.019 & 0.001 & -0.004 & -1.90 & 0.15 & -0.40 \\
\hline Having PTRPA & & & & & & & & & & & & & & & & \\
\hline No & 0.000 & 0.000 & 0.000 & 0.000 & 0.000 & 0.000 & 0.059 & 0.000 & 0.000 & 0.000 & 0.000 & 0.000 & 0.000 & 0.00 & 0.00 & 0.00 \\
\hline Yes & $0.279^{*}$ & -0.014 & 0.052 & 0.279 & -0.014 & 0.052 & -0.059 & -0.017 & 0.001 & -0.003 & -0.181 & -0.004 & -0.022 & -18.07 & -0.43 & -2.18 \\
\hline Sum & & & & & & & & -0.017 & 0.001 & -0.003 & -0.181 & -0.004 & -0.022 & -18.07 & -0.43 & -2.18 \\
\hline Having PWRPA & & & & & & & & & & & & & & & & \\
\hline No & 0.000 & 0.000 & - & 0.000 & 0.000 & - & -0.141 & 0.000 & 0.000 & - & 0.000 & 0.000 & - & 0.00 & 0.00 & - \\
\hline Yes & $0.425^{*}$ & 0.040 & - & 0.425 & 0.040 & - & 0.141 & 0.060 & 0.006 & - & 0.653 & -0.029 & - & 65.27 & -2.92 & - \\
\hline Sum & & & & & & & & 0.060 & 0.006 & - & 0.653 & -0.029 & - & 65.27 & -2.92 & - \\
\hline Total observed & & & & & & & & 0.103 & -0.107 & 0.064 & 0.435 & 0.953 & 0.741 & 43.54 & 95.31 & 74.10 \\
\hline Residual & & & & & & & & -0.011 & -0.084 & 0.077 & 0.565 & 0.047 & 0.259 & 56.46 & 4.69 & 25.90 \\
\hline Total & & & & & & & & 0.092 & -0.191 & 0.141 & 1.000 & 1.000 & 1.000 & 100.00 & 100.00 & 100.00 \\
\hline
\end{tabular}

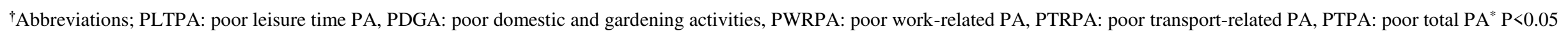



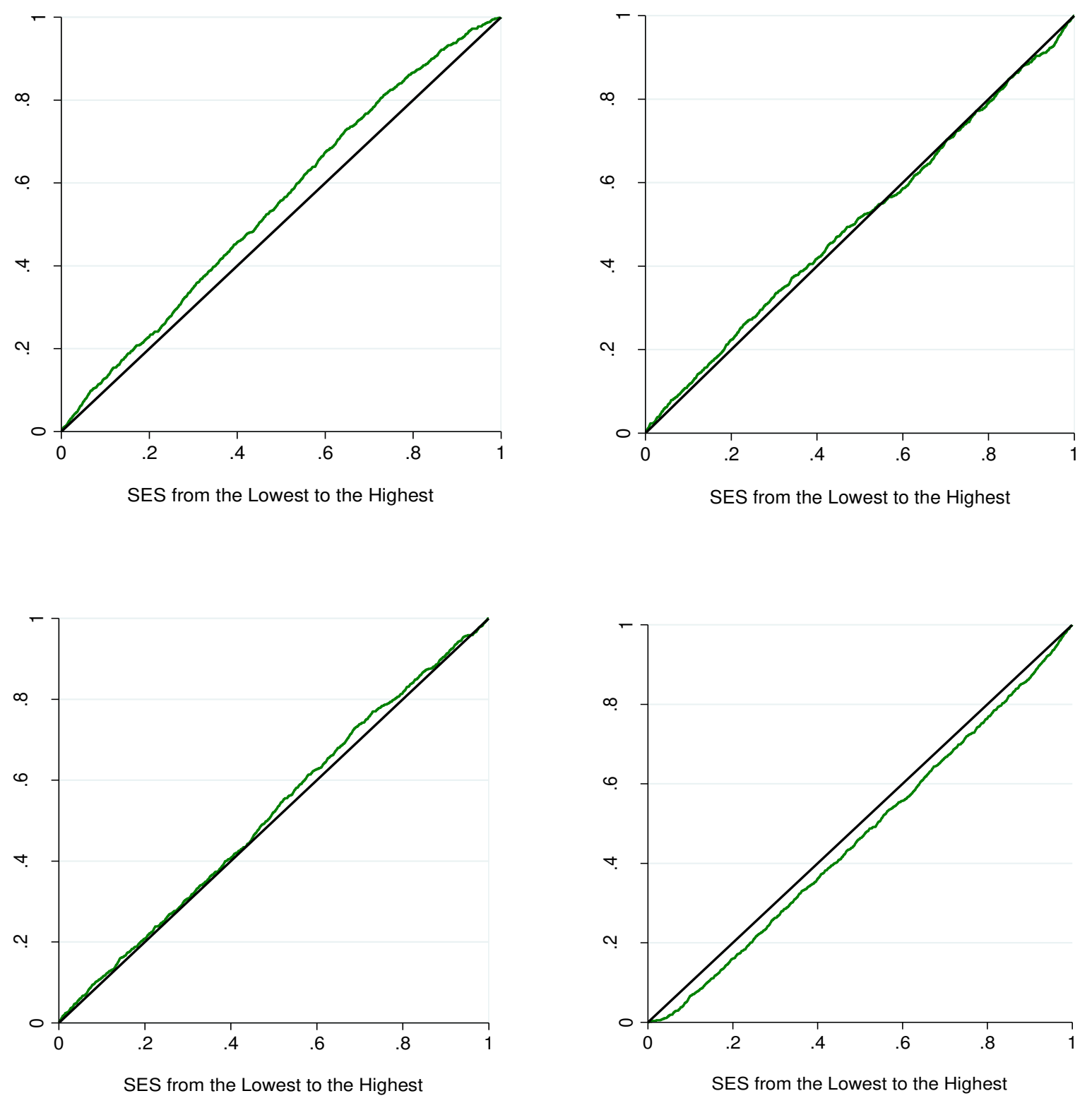

498 


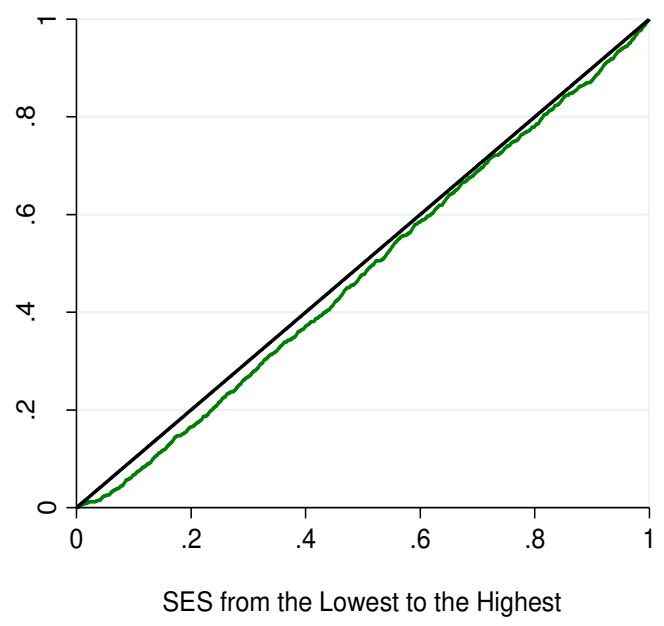

501

502 Figure 1. Concentration curves for all types of PPA among staff of Medical Sciences 503 University in Shahroud, Iran 